\title{
Comércio e circulação de livros entre França e Portugal na virada do século XVIII para o XIX ou Quando os ingleses atiraram livros ao mar
}

\author{
commerce and circulation of books between France \\ and Portugal at the turn of the $18^{\text {th }}$ to the $19^{\text {th }}$ Century \\ or When the British threw books overboard
}

Cláudio DeNipoti*

\section{RESUMO}

Este trabalho busca investigar algumas formas de comércio e circulação de livros em Portugal, na virada do século XVIII para o XIX, através do estudo da correspondência que Marino Miguel Franzini trocou com livreiros europeus - franceses, em especial - e agentes comerciais responsáveis pela aquisição e transporte dos livros até Portugal. A documentação concentra-se principalmente nas décadas anteriores ao movimento liberal, compondo-se de listas de livros (solicitadas ou entregues), catálogos de obras, faturas, listas de livrarias e cartas trocadas entre Franzini e pessoas ligadas ao comércio de livros. As pistas fornecidas pela documentação reforçam a noção de que a literatura filosófica iluminista e liberal em Portugal foi amplamente disseminada por mecanismos que variavam da compra direta, intermediada por livreiros, marinheiros e mercadores, até o contrabando e a contrafação, realizada por imigrantes e agitadores liberais de diversas nacionalidades.

Palavras-chave: história do livro; idéias liberais; redes de comércio.

\section{Abstract}

This is an attempt at investigating some of the ways books were circulated in Portugal in the late $18^{\text {th }}$ and early $19^{\text {th }}$ Century, analyzing the letters exchanged between Marino Miguel Franzini and European booksellers - particularly French, or in France - and commercial agents responsible for acquiring or dispatching the books to Portugal. The documents are concentrated in the decades immediately preceding the liberal movement, and are made up of lists of books (ordered or delivered), book catalogues, invoices and personal letters. These papers show information which strengthens the idea that, in Portugal, the philosophical enlightened literature was broadly spread, through processes which varied from direct purchase, mediated by booksellers, sailors and merchants, to contraband and counterfeiting, done by immigrants and liberal agitators of various nationalities.

Keywords: book history; liberal ideas; commerce networks.

\footnotetext{
* Departamento de História, Universidade Estadual de Ponta Grossa (UEPG). R. Dr. Faivre, 319, ap. 303. 80060-140 Curitiba - PR - Brasil.denipoti@yahoo.com.
} 
As formas de disseminação das idéias liberais em Portugal, na virada do século XVIII para o XIX, têm sido alvo de investigação acadêmica sistemática, preocupada, particularmente, com os mecanismos intelectuais de apropriação das idéias do Iluminismo além-Pireneus e, posteriormente, do liberalismo. O Iluminismo português foi caracterizado, em diversos momentos, como "utilitarista", com um "triunfo esmagador do empirismo britânico numa extensão inigualada em qualquer outro lugar". ${ }^{1}$ Essa supremacia ocorreu com a importação de idéias (e livros), principalmente a partir de Nápoles, de Roma e do sul da França, após a década de 1730.

O empirismo e as idéias britânicas foram, de fato, a alavanca que estilhaçou a dominação escolástica sobre a cultura Ibérica e moldou o Iluminismo Ibérico e Ibero-Americano... Em Portugal, o último país na Europa em que o aristotelismo escolástico reinou supremo... [na década de 1750], nenhuma figura de ponta contestava ou duvidava que Bacon, Boyle, Locke e Newton forneciam a melhor base intelectual para um Iluminismo moderado e viável. (Israel, 2001, p.536-537)

Os historiadores aceitam, de forma mais ou menos unânime, que o ápice do utilitarismo se deu durante a gestão pombalina, e aceitam (não tão unanimemente) que as práticas administrativas inspiradas nessa visão de ciência e sociedade foram continuadas, ao longo do restante do século XVIII, pelas administrações de D. Maria e D. João VI. ${ }^{2}$ José Esteves Pereira apresenta, de modo sucinto, o debate sobre a Ilustração portuguesa:

No que diz respeito à maior ou menor assunção das Luzes, em Portugal, importa dizer, também, que elas se vão assumindo, sinuosamente, em significação que não é só fruto de condicionamentos institucionais ou da repressão do poder face ao saber e de afirmações claras desse saber efectivamente emancipado (ligado ao interesse marcado de uma pedagogia que, de facto, em meios ilustrados se quer, apostadamente, assumir). É também aqui que nos afastamos das Luzes da Enciclopédia, na exacta medida em que as hesitações e as resistências aproveitavam ao desejo de insurgência anti-racionalista, anti-enciclopedista, antipositivista, subseqüentes com destinatário certo e atento. ${ }^{3}$

De forma similar, as idéias liberais, herdeiras dos princípios iluministas, foram rapidamente aceitas e disseminadas em Portugal e em seu império, incorporando elementos que permitem perceber que "o Reformismo ilustrado português articulou as Luzes com um substrato cultural anterior", mantendo vivas idéias como a de um império luso-brasileiro centrado no Brasil. ${ }^{4}$ Esse 
reformismo compartilhava as características do Iluminismo europeu de provocar "transformações na esfera das sociabilidades e da circulação de textos impressos", ao mesmo tempo em que o Estado utilizava práticas administrativas que objetivavam racionalizar e controlar a riqueza e as populações, sempre mantendo, como objetivo maior, o bem da humanidade. ${ }^{5}$ Segundo Luís de Oliveira Ramos, "por ser um país de intensas relações mercantis, onde a burguesia medrava, Portugal dispunha então de condições que proporcionavam a recepção das novas doutrinas e propostas de mudança veiculadas já através do movimento ilustrado, já assumidas e transmitidas pelas revoluções atlânticas ocidentais que têm o seu acume na Revolução Francesa" (Ramos, 1988, p.135).

Acredita-se que os livros que transmitiam as idéias iluministas e liberais tinham uma circulação ampla em Portugal durante a segunda metade do século XVIII e as décadas iniciais do século XIX. Ramos afirma que "afluía ao Reino um bom número de publicações - livros, jornais e panfletos — oriundos do exterior, e nas nações européias estudavam por esse tempo portugueses que continuavam em ligação com a mãe pátria" (1988, p.135-136); Diogo Ramada Curto explica que "ao longo do último quartel do século XVIII, o comércio internacional do livro conhece também um dos seus momentos áureos, cabendo a Portugal uma parcela importante na procura do livro, sobretudo em língua francesa". ${ }^{6}$ Essa ligação comercial e pessoal manteve a nação portuguesa (e seu império ${ }^{7}$ ) atenta às "luzes do século" e aos fenômenos revolucionários. Quando não eram obtidos legal e oficialmente, como é o caso do Mosteiro de Tibães e do Arcebisbo de Braga, que compraram a Encyclopédie quando do seu lançamento, ${ }^{8}$ os livros eram conseguidos por meio de viajantes, diplomatas, além do contrabando, puro e simples, às vezes executado pelos próprios livreiros estabelecidos nas principais cidades portuguesas. ${ }^{9}$

O objetivo deste trabalho é contribuir para a ampliação do conhecimento sobre os meios pelos quais os livros foram comercializados na Europa, através do estudo da correspondência que o comendador português Marino Miguel Franzini trocou com livreiros europeus e agentes comerciais responsáveis pela aquisição e transporte dos livros até Portugal.

Marino Miguel Franzini, nascido em Lisboa em 21 de janeiro de 1779, era filho do matemático veneziano Miguel Franzini - professor da Universidade de Coimbra, trazido para Portugal no processo de "importação portuguesa do iluminismo italiano" das reformas universitárias pombalinas, juntamente com outros pensadores e intelectuais como "Vandelli, Ciera, Dolla 
Bella, Brunelli, Faciolatti...”. ${ }^{10}$ Foi incumbido de ensinar matemática aos filhos da rainha D. Maria, D. José e D. João.

Em sua carreira, Marino Franzini acumulou diversos cargos militares, burocráticos e honoríficos (Vogal do Supremo Conselho de Justiça Militar, Brigadeiro da Real Marinha, Subdiretor do Arquivo Militar, Comendador da Ordem de Cristo e Par do Reino); dedicou-se a estudos hidrográficos, econômicos e estatísticos, relacionados à sua carreira na Marinha Real Portuguesa - juntamente com José Bonifácio de Andrada e Silva, foi um dos responsáveis pela criação da Sociedade Real Marítima Militar e Geográfica, em 1798. Concomitantemente com a atuação científica, Franzini participou de forma intensa da implantação do regime liberal de 1820, tendo sido ministro da Fazenda e da Justiça por dois breves períodos (1847 e 1851) e deputado nas Cortes Constituintes (1820 e 1837) e Ordinárias (1822). Sua atuação científica rendeu-lhe o reconhecimento como o fundador dos estudos meteorológicos e geológicos em Portugal, associando sua imagem pessoal à do cientista competente e imparcial, sem os excessos - principalmente políticos - que caracterizam a clássica imagem revolucionária. Graças à criação da imagem de competência neutra, pode-se afirmar que Franzini tornou-se "um símbolo reconhecido do 'progresso', enquanto paradigma do utilitarismo da ciência, face às vivências reais de uma sociedade". ${ }^{11}$

$\mathrm{Na}$ condição de homem do progresso e da ciência, Franzini reuniu, ao longo da vida, uma importante biblioteca, deixando sobre ela expressivo corpo documental, o qual possibilitou o presente estudo. ${ }^{12}$ Tal documentação concentra-se principalmente nas décadas anteriores ao movimento liberal, compondo-se de listas de livros (solicitados ou entregues), catálogos de obras, faturas, listas de livrarias e cartas trocadas entre Franzini e pessoas ligadas ao comércio de livros. Com 42 documentos, 92 páginas de texto, a documentação pode ser dividida em dois grupos temporalmente distintos. O primeiro, iniciado nos anos finais do século XVIII, reúne dois textos do próprio Marino Franzini sobre seus livros. O Catálogo da Livraria de Marino Miguel Franzini, escrito provavelmente entre 1798 e 1811, com base em concepção do conhecimento que exclui dele a religião ou a metafísica (uma edição holandesa de 1757 da Bíblia, em italiano, foi classificada como "obra clássica", e o Alcorão, como obra literária), apresenta 816 livros e 949 volumes de sua propriedade naquele período. Ainda que não existam informações sobre que destino tiveram os livros e mapas colecionados por Franzini, cujas referências permeiam toda a documentação, deve-se notar que sua biblioteca era um importante instrumento de trabalho - e a forte presença de cartas e mapas reitera isso, 
pois são essenciais na vida de um marinheiro que também foi geógrafo e cartógrafo. Cientista, militar, liberal, ele organizou seu catálogo de livros como concebia o mundo: com ênfase nas facetas de sua própria vida, criticando de forma sutil - pela classificação do conhecimento que estabeleceu no documento, mas também por silêncios - a preponderância da religião em Portugal no final do século XVIII. ${ }^{13}$

O Rol dos livros que comecei a comprar em 1798 lista os livros comprados por ano e o local de compra, incluindo os gastos anuais com livros entre 1798 e 1807, informações sobre encadernadores, fretes e impostos, como, por exemplo, na anotação feita em outubro de 1799: "Estas duas cartas, compradas em Veneza na loja de Theodore Viero. Nota: O meu encadernador de Veneza, da estamparia Pinoli... leva por huma encadernação ordin. ${ }^{a}$ de papelão azul... L 1 1/2...". ${ }^{14}$

O segundo grupo de documentos compreende faturas detalhando os livros solicitados ou efetivamente comprados por Franzini, catálogos de livreiros, sugestões de leitura e informações variadas sobre o comércio de livros, documentos escritos entre 1814 e 1824, incluindo também cartas e bilhetes de livreiros, capitães de navio ou agentes responsáveis pelas compras e pelo transporte de livros de várias partes da Europa até Lisboa.

Havre, 4 de outubro de 1819

Por ordem dos $S^{\text {srs }}$ Mascarenhas \& Comp ${ }^{a}$ de Paris temos feito embarcar sobre o navio frances, les Trois Soeurs Unis, Cap. ${ }^{\mathrm{m}}$ Vacquerie, huma caixa $\mathrm{p}^{\mathrm{a}} \mathrm{V} . \mathrm{S}$ da qual junto lhe remetemos o conhecim. ${ }^{\text {to }}$.

Este navio se propõe em sair de 15 a 20 do corre se o tempo o permitir.

Piamont \& Cia.

Centrando nossa análise na experiência particular de Marino Miguel Franzini, podemos tentar perceber alguns dos mecanismos do comércio de livros e, conseqüentemente, da circulação de idéias na Europa da virada do século XVIII para o XIX. Como funcionava, portanto, o comércio de livros - legais e ilegais - que supriram a biblioteca de Marino Franzini e, muito provavelmente, de diversos de seus contemporâneos em Lisboa, Veneza ou Madri?

Em primeiro lugar, como se vê na Tabela 1, Franzini comprou uma grande quantidade de livros ao longo de mais de três décadas, entre 1798 e 1825. Os números da tabela foram retirados dos documentos que permitem quanti- 
ficar, efetivamente, em títulos e/ou volumes, essas compras, quais sejam: o Rol dos livros... para o primeiro período e cerca de onze faturas e listas para o segundo. Ainda que uma grande quantidade das cartas faça alusão direta à compra de livros, em geral, elas se referem a "caixas", "volumes" ou "pacotes", sem muitas especificações sobre quais ou quantos livros continham. Esses documentos permitem aferir um total de 686 títulos (com um número de volumes maior, pois era comum a edição de livros em vários volumes) adquiridos durante todo o período.

Tabela 1

Total de livros comprados por Marino Miguel Franzini

\begin{tabular}{ccc}
\hline Período & Títulos & Volumes \\
\hline $1798-1805$ & 277 & - \\
$1814-1825$ & 409 & 760 \\
\hline
\end{tabular}

O Rol... fornece evidências detalhadas sobre a origem dos livros comprados por Franzini. O texto é iniciado com a frase "Livros que compramos no Negocio Molini de Florencia"; com o subtítulo "Veneza 1798", segue uma lista de 27 títulos em francês, começando pelo Traité de calcul différentiel e intégral de Cousin, publicado em Paris, em 1796; diversos relatos de viagens de descobrimento do século XVIII - incluindo o livro dedicado aos Détails nouveaux et circonstances sur la mort du Capitain Cook, publicado em Londres em 1786; outros tantos ligados a assuntos militares, como a Campagne du Général Buonaparte en Italie (Paris, 1798), e a assuntos diversos, como a Dissertation sur les maladies produites par la masturbation, de Samuel Tissot (Lausanne, 1785). Franzini incluiu observações sobre o destino dado a alguns dos livros, como o Les Jardins de De Lille: "deste livrinho fizemos presente ao Srn. Pinali”.

Franzini listou seis títulos, na seqüência do Rol..., "livros e cartas que me foram provistas pelo Sñr João Piaggio Consul Portugues em Genova”, entre 1798 e 1799. Mesmo que informalmente, o recurso a agentes que efetuavam as compras de livros era algo comum para os leitores portugueses do final do século XVIII e início do XIX. Em 1802, por exemplo, D. Rodrigo de Souza Coutinho solicitou

ao ministro de Portugal em Haia, João Paulo Bezerra de Seixas, o envio de livros que tratassem pormenorizadamente dos impostos de selo estabelecidos em Inglaterra, bem como do próprio impresso contendo "le Bill de l'Income tax"; o 
mesmo se passando quanto à traducção para o francês de Adam Smith, "avec des notes", bem como com os "papiers publics de France qui y parrissant tels que ceux des sciences, statistiques et de commerce"; pretendendo também saber qual a livraria em Haia de onde poderia encomendar livros novos. (Curto, 2007, p.250)

O Rol... é particularmente interessante por delinear o percurso dos livros comprados por Franzini até chegarem às suas mãos. Sobre Le pilote de TerreNeuve, por exemplo, publicado em Paris em 1784, constam as seguintes despesas:

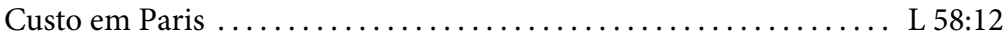

Diligencia de Paris athé Genova..................... L 9:7

Enfardam. ${ }^{\text {to }}$ em Paris............................. L $6: 4$

Caixinha feita em Genova ........................ L 3:2

Porte de Genova athé Veneza pela via de Parma e Bolonha ...... L L 21:9

Total: L98:13

Todos os outros livros seguiram percursos semelhantes, saindo da França em direção a Veneza ou Florença, passando por Milão, Gênova ou Parma. Connaissance des temps pour l'année VII de la République foi de Paris a Gênova, onde foi enfardado, transportado até Florença e colocado no correio para Veneza. Carte général de l'Océan Atlantique ou Occidental (Paris, 1786), por sua vez, foi de diligência da França até Gênova, para ser enfardado juntamente com outros livros e então seguir pelo correio até Milão e de lá até Veneza. Supomos que a viagem até Lisboa tenha sido feita por um dos muitos navios venezianos utilizados no comércio com Portugal havia vários séculos. ${ }^{15}$

As anotações de compras se sucedem: em junho de 1799, três livros comprados do Livreiro Soapin, em Pádua, e um na loja de Theodoro Viero, em Veneza; em outubro de 1799, três livros comprados no "Negócio Molini" de Florença e dois mapas comprados de Theodoro Viero; em junho de 1800, 11 livros comprados em Siena, inclusive o Emile de Rousseau e as Méditations de Volney; em agosto do mesmo ano, seis títulos adquiridos em Lisboa, todos abordando assuntos jurídicos ou militares. A seguir, o Rol... apresenta livros comprados em Siracusa em 1800 (seis livros, em italiano) e duas gramáticas da língua francesa redigidas em inglês, publicadas em Londres e compradas em "P. ${ }^{\text {to }}$ Mahon" (Maó, em Minorca) em janeiro de 1801. Em março daquele ano, Franzini comprou em Lisboa três livros relacionados ao aprendizado da língua inglesa e um manual de estenografia. Para maio de 1801, há uma lista 
de 32 títulos que Franzini adquiriu em L'Orient, na Suíça, a cerca de 170 quilômetros de Monestier de Briançon - cidade natal da maioria dos livreiros estabelecidos em Lisboa desde meados do século XVIII, notadamente Bertrand, Chardron e Guérin, entre outros (Guedes, 1987, p.15; Curto, 2007, p.222-226).

Essa lista em particular chama a atenção no Rol..., primeiro, por ser menos detalhada que as anteriores, as quais traziam nome do autor, local e ano de edição, formato e indicação de tradução e, como no caso das obras compradas por intermédio de João Piaggio, detalhes dos custos de transporte. Aqui, só os nomes dos livros são mencionados. Em segundo lugar, a lista contém os livros que Franzini anotou no Catálogo... sob o título de "Galanteria". A maioria deles foi estudada extensivamente por Robert Darnton em seus textos sobre os diferentes universos da palavra impressa. ${ }^{16}$ Estão relacionados no Catálogo..., nesta ordem, L'Académie des dames, que é, segundo Darnton, "um best seller pornográfico que, desde seu lançamento em 1680, passara por várias metamorfoses" (Darnton, 1998, p.105-130); Le compère Mathieu; La fille de joie; Le diable boiteux (do qual Franzini já adquirira um exemplar em Siena, no ano anterior); La religieuse (de Diderot); L'enfant du carnival; e, por último, aquela que provavelmente foi a principal obra do gênero, definida por Darnton como um bildungsroman - o relato de uma educação, neste caso, para o prazer: Thérèse philosophe (anotada por Franzini como Thérèse la philosophe), em uma edição com dois volumes, feita em Bruxelas em 1784.

O que o autor do Catálogo definiu como "Galanteria" é, portanto, aquilo que os editores, livreiros e leitores do século XVIII denominavam "livros filosóficos", ainda que "por filosofia os homens do livro sob o Ancien Régime entendessem não as Luzes, mas um setor crucial do comércio livreiro do século XVIII, o do ilícito, do interdito e do tabu" (Darnton, 1992, p.14). Além desses, Franzini comprou em L'Orient La nouvelle Héloïse, Robinson Crusoë e Les passions du jeune Werther. O restante dos livros refere-se essencialmente a obras militares. As compras em L'Orient continuaram em 4 de maio de 1801 (que Franzini anotou como 14 floréal, an 9, dando pistas de uma adesão tácita aos ideais da República Francesa) incluindo 68 cartas e mapas comprados chez Duquesnel.

Como diversos outros livros anotados na documentação, muitas dessas obras eram proibidas em Portugal e sofriam a ação censória das instituições de controle criadas na gestão pombalina. ${ }^{17}$ Mesmo assim, os livros estrangeiros, em especial os franceses, eram acessíveis aos súditos da Coroa tanto em Lisboa quanto no Porto ou em Coimbra por uma série de estratagemas, como 
manter os livros proibidos fora das vistas nas lojas dos livreiros, para cedê-los "a clientes de confiança e a quem dispusesse de permissão régia para os utilizar", "pedir a um marinheiro, a um viajante, a um diplomata para fazer a sua compra no estrangeiro" ou simplesmente consultar as bibliotecas dos oficiais estrangeiros a serviço do exército português (Ramos, 1988, p.137).

A compra seguinte, em junho de 1801, foi feita em La Coruña, na Galícia, e incluía uma dúzia de mapas diversos comprados do livreiro D. Manuel de Soto que, para decepção (devidamente anotada) de Franzini, não possuía outra dúzia de mapas que ele desejava. O ano de 1802 surge no Rol... com anotações de despesas feitas em Lisboa, com livros adquiridos nos anos anteriores. São descritas encadernações e "associações” (a reunião de diversos títulos em um único volume, como uma "Associação de Gazetas”, que Franzini mandou fazer em 27 de outubro). Conforme os registros, as compras de livros foram menos constantes e dizem respeito a cinco volumes, adquiridos em $29 \mathrm{de} \mathrm{ju-}$ lho e 27 de outubro. Há também uma interessante pista sobre os métodos de comércio. Franzini afirmou que nessa última data vendeu "aos livreiros" uma série de livros, inclusive o Tratado de cálculo diferencial de Cousin, que comprara em Veneza, em 1798:

1 Manuel de l'Artillerie de Durtubie antigo $-600^{\mathrm{rs}}=1 \mathrm{C}$. ${ }^{\text {ta }}$ de Vérdum do mar du N. ${ }^{\text {te }}$ e do Oceano pacifico $-1 \$ 200=$ Obra de Clarice d'Harlowe 10 vol. $12^{\circ}$ por $2 \$ 300 .=$ Cousin Traité du calcul differ. ${ }^{\mathrm{el}}$ et integral 2 vol. $4^{\circ}$. rel. Paris 1796 $-3 \$ 800-$ Sejour. Traité des mouvem. ${ }^{\text {te }}$ appar. ${ }^{\text {te }}$ des Corps celestes 2 V. $4^{\circ}$ rél. $-7 \$ 200-$ Bossuet Calcul differ. ${ }^{\text {el }}$ et integral 2 V $8^{\circ} 3 \$ 000$

O restante do Rol..., de maneira mais escritural, lista compras e despesas com livros entre 1803 e 1807, mês a mês, freqüentemente indicando os dias das compras, mas não mais o local ou o livreiro. Foram 13 títulos em 1803, 17 em 1804, 4 em 1805, 28 em 1806 e 15 em 1807.

A documentação relativa ao segundo período (1814-1825) não foi escrita pelo próprio Marino Miguel Franzini, mas em grande parte pelos livreiros, agentes e amigos que se empenharam em trazer-lhe os livros que pedia ou desejava, compreendendo um total de 35 documentos distintos. Mais dificilmente quantificável, exceto como démarche analítica, ela nos permite aprofundar as noções aventadas até aqui sobre estratégias e mecanismos envolvidos no comércio europeu do livro.

O destaque inicial deve ser dado, como mencionado anteriormente, à onipresença francesa nesse comércio, seja pela nacionalidade de autores e li- 
vreiros, seja pelo idioma em que a maior parte dos livros foi escrita. No Catálogo..., 39,8\% dos livros foram impressos na França (324, em um total de 816 títulos, dos quais foi possível identificar o local de edição) e $68 \%$ dos livros foram publicados em francês (445, em um total de 652 títulos). Some-se a isso o fato de os mais importantes livreiros portugueses serem de origem francesa (Guedes, 1987, p.15-16). Acrescentemos também que, na documentação de Marino Franzini, essa onipresença francesa se manifesta na origem das encomendas, no idioma dos livros e mapas comprados e dos catálogos recebidos. Entre os papéis avulsos analisados, existe uma lista de livreiros franceses com seus respectivos endereços parisienses anotados. Podemos compreender melhor esses dados se pensarmos, como Franklin Baumer, que a influência intelectual francesa sobre o resto da Europa era inquestionável, "fornecendo a nova língua franca, e instituições e idéias, incitando novos movimentos no mundo do pensamento e da acção".$^{18}$ Essa preponderância ocorria principalmente pelo fato de que, "sendo o país mais poderoso, populoso e culto da Europa, a França era uma nação em fermento, descontente com o seu Ancien Régime e pensando seriamente em mudar para melhor" (Baumer, s.d., p.180, grifo do original). Embora exista aqui uma aparente contradição com o enquadramento teórico sobre o Iluminismo português aqui apresentado - que enfatiza a influência predominante do utilitarismo de origem inglesa - , as obras de Bacon, Newton e Smith entravam em Portugal, também elas, predominantemente em traduções francesas e, mais raramente, portuguesas. Isso é verificável na biblioteca de Marino Miguel Franzini, mas é corroborado por estudos complementares sobre a circulação e a leitura de livros no período. É possível pensar nas hipóteses levantadas por Fernando Guedes para explicar o baixo número de traduções no mercado editorial português do final do século XVIII e início do XIX.

Será legítimo assumir que a camada culta da população portuguesa era tão bilíngüe na época e tão tributária da cultura francesa (ainda que média ou baixa), tão empertigada no seu francês que não gerava ambiente próprio ao aparecimento de traduções das melhores obras dessa mesma França que tanto admirava? Ou essa camada era tão diminuta que não justificava o investimento na tradução...? (Guedes, 1987, p.145; ver também Lisboa, 1991, p.68-69).

Quaisquer que sejam as razões, a inegável preponderância da cultura francesa sobre o mercado editorial e o comércio de livros fica patente nas compras feitas por Franzini, mesmo aquelas realizadas em Portugal. Entre 
1821 e 1823, Franzini utilizou os serviços de Borel \& Borel, livreiros francoportugueses cuja loja era vizinha àquela dos Bertrand, em Lisboa (Lisboa, 1991, p.37). Deles, Franzini adquiriu 60 títulos, todos em francês e faturados em francos, com cálculos de conversão para réis.

Tabela 2

Compras de Marino Miguel Franzini na loja de Borel \& Borel

\begin{tabular}{c|c|c|c|c}
\hline Ano & Títulos & Volumes & \multicolumn{2}{c}{ Valor pago } \\
\hline & & Francos & $\begin{array}{c}\text { Réis } \\
\text { (inclui despesas adicionais } \\
\text { de frete e comissão) }\end{array}$ \\
\hline 1821 & 8 & 15 & 68,00 & $12 \$ 320$ \\
\hline 1822 & 31 & 46 & 252,40 & $59 \$ 353$ \\
\hline 1823 & 21 & 41 & 257,45 & $54 \$ 820$ \\
\hline Total & 60 & 102 & 597,85 & $126 \$ 993$ \\
\hline
\end{tabular}

Do mesmo modo que João Piaggio atuara como agente de Franzini em 1798, recebendo os livros que percorriam o caminho por terra entre a França e Portugal até a Itália, os irmãos Borel eram o elo final de uma rota marítima mais direta (e próxima). Os livros que eles venderam a Franzini e seus contemporâneos lisboetas vinham diretamente do Havre a Lisboa. A consolidação do poderio napoleônico, e sua queda final em 1815, modificaram significativamente as rotas comerciais ao longo dos anos em foco, de maneiras bastante peculiares.

De qualquer maneira, em 1819 e 1820, é possível delinear de forma bastante clara as operações de comércio que tinham como comprador final o Comendador Franzini. Tal delineamento pode ser obtido seguindo-se às avessas o percurso feito por uma caixa de livros comprados por ele, contendo 55 títulos (88 volumes), com a habitual ênfase em livros de viagem, como Voyage en Egipte par Vivant Denon (Paris, 1802); relacionados a estudos geográficos, como Agenda du Voyageur Géologue de Horace Saussure (Genebra, 1796); ou tabelas meteorológicas, como o Tableau des vents etc. de Rome; mas que incluía também obras como De la fabrication de la farine de pomme de terre de André Beaumont (1816), De la influence des femmes sur la littérature 
de Julien-Joseph Virey (1810), L'ami de la santé de Philibert Perier (1808), além de um conjunto de Lunettes périscopiques p. Mess. Travassos.

A caixa com livros impressos foi liberada por Franzini em 8 de novembro de 1820, no Desembargo do Paço, em Lisboa, mediante a quantia de 780 réis por "Moras ... Contribuição ... Descárga ... Arrumação no Armazem ... Registro da Provizão ... A quem arrumou os livros e consertou a caixa ... Abertura, e por fora ... Carreto ao Dezemb. ${ }^{\circ}$ do Paço". ${ }^{19}$ Três dias depois, Franzini pagou o equivalente a 621,60 francos $(133 \$ 330)$ ao livreiro P. Le Fevre, que, por sua vez, pagara 3\$089 a Francisco Perfumo "Consignatario do Navio Jupiter" pelo frete de "hum volume", no dia 26 de outubro daquele ano. Franzini anotara, no verso da fatura e recibo de P. Le Fevre, que aqueles livros "forão remetidos de Paris em Outubro de 1820 no navio Júpiter”. Finalmente, encontramos quatro páginas anotadas por S. D. Mascarenhas \& Co., de Paris - de quem Franzini já comprara 34 títulos, com 84 volumes no ano anterior, também envolvendo Francisco Perfumo, dessa vez responsável pelo navio Trois Sœurs Unies, no qual "Piamont e Co." despachara os livros - intituladas Fourni à Monsieur Marino Miguel Franzini le 25 juillet 1820. A documentação é complementada por uma "nota sobre os livros pedidos mas que não foram enviados", em sua maioria por estarem esgotados ou em falta, e uma "Nota de livros q não vão por não se terem achado" escrita em português e também assinada S. D. Mascarenhas \& Co.

Temos, assim, um livreiro português em Paris que despachou livros solicitados por Franzini ao porto do Havre. Lá, embarcados no navio Jupiter, sob responsabilidade de Francisco Perfumo, os livros foram entregues a um livreiro de origem francesa estabelecido em Lisboa (P. Le Fevre), a quem, possivelmente, Franzini tinha feito o pedido original. Marino Miguel pagou impostos e taxas, chegando à conclusão de que "as despesas de Transporte equivalem a $12 \%$ sobre o custo (A) primitivo dos livros”, e pôde desfrutá-los exatos 105 dias após terem saído de Paris.

De modo semelhante, em 13 de novembro de 1824, o livreiro veneziano Andrea Santini Figlio enviou uma caixa com 24 títulos e 82 volumes "por ordem do ... Comendador Marino Franzini”, que incluíam a obra completa de Goldoni, os Opúsculos de Plutarco e diversos títulos de geografia e agricultura, todos em italiano. Remetida a bordo do "brigantino austríaco l'Arpocrate", a caixa de livros foi acompanhada por um pacote contendo "dois chapéus ... uma gargantilha e um cordão de pérolas" que a Condessa Anna Frangini [sic], ou viúva Anneta Gervasoni, nascida Franzini, súdita portuguesa, enviou para a Condessa Sebastiana Franzini, em Lisboa. ${ }^{20}$ Sobre relações de parentesco 
dessas mulheres com Marino Miguel, ainda que não tenha sido possível descobrir quais eram, é inegável que existiam.

Ambos os volumes foram deixados aos cuidados de Alessandro Gililieb, capitão do Arpocrate, para "salvo arrivo in Lisbona", contra a restituição dos valores pagos por ele a Santini Figlio.

Em 23 de maio de 1814, um agente anônimo anotara um "catalogue des livres et cartes demandés par M. M. Franzini”, com 36 livros e três mapas, além de uma pequena lista de três títulos solicitados, mas não localizados. Essa compra dá ênfase, novamente, a obras militares, como a Mémoire au sujet des Places fortes que doivent être démolies ou abandonnées de Lazare Carnot (Paris, 1789), e científicas, como o Traité analytique sur le calcul des probabilités de Pierre-Simon de Laplace (Paris, 1812). Mas também inclui obras de "diversidades", como o Lavater des Dames ou L'Art de connaitre les femmes sur leur physionomie de Johann Caspar Lavater (Paris, 1810).

Merece destaque a inclusão de um Catalogue des livres rares \& précieux etc. du Cabinet de Firmin Didot (1810), pois indica uma forma de atualização sobre as novidades editoriais. Essa prática, sintomática da inserção de Franzini no universo da palavra impressa e da circulação de idéias, pode ser verificada em outros documentos seus, como um Catalogue d'ouvrages choisis de la Bibliothèque de Dulau, além de diversas indicações que Franzini ganhava ou solicitava tais catálogos de seus agentes com regularidade.

Um último exemplo dos mecanismos comerciais utilizados por Franzini (e seus contemporâneos, em diversas partes da Europa e provavelmente também das colônias e ex-colônias) diz respeito à maior compra documentada nos papéis avulsos legados por ele à posteridade. A "Fatura dos livros comprados por contas e ordem do Ill. ${ }^{\text {mo }}$ Snr Marino Miguel Franzini Ten. ${ }^{\text {te }}$ Coronel da Brigada R.l da Marinha em Lisboa”, de 1816, elenca 190 títulos, 390 volumes, comprados em Paris a um custo de 1.328,25 francos, com 31,10 francos por despesas de "emballage et expédition". Embora o conteúdo dos livros adquiridos mereça, por si só, um estudo adequado, a atenção aqui se dirige à transcrição da carta do agente (infelizmente, inominado) responsável pela compra. Na carta, datada de 30 de março de 1816 e recebida por Franzini em 19 de abril do mesmo ano, o agente parisiense de Franzini explicou (em bom português) que se esforçou para seguir as instruções de compra e tentou informar Franzini, em diversas cartas anteriores, para as quais não obteve resposta.

[Nelas] lhe dava conta de varias diligencias que eu havia feito em abóno do credito de VS. ${ }^{a}$ em materias scientificas, e dos resultados que obtive. Como não 
haja alcançado resposta alguma sua que approvasse os passos que dei, sem me serem prescritos por VS'a, conformo me com a vulgar sentença de recorrer a quem me encommendou o sermão, de que não esperava outra paga que a certeza em que VS. ${ }^{a}$ houvesse de ficar da m. ${ }^{a}$ sincera amisade. ${ }^{21}$

Ao conseguir reunir todos os livros solicitados, o agente entregou ao "Sñr G. ${ }^{\text {me }}$ de Rouve" a fatura do carreteiro responsável pelo transporte entre Paris e o porto do Havre, em 26 de março. De Rouve pagou ao agente os 1.359,35 francos e, como Francisco Perfumo e Alessandro Gililieb, tornou-se o responsável pela carga. Não há indicações sobre a participação de algum livreiro português na transação, levando a supor que Franzini preferiu, neste caso, diminuir o número de intermediários, tendo em mente os custos globais.

Considerando a viagem marítima e a fragilidade da mercadoria, os cuidados dispensados aos livros em sua caixa geravam preocupação.

Dezejo e espero que ella chegue a salvam. ${ }^{\text {to }} \mathrm{e} \mathrm{bem} \mathrm{tratada.} \mathrm{Leva} \mathrm{a} \mathrm{marca} \mathrm{M.M.F.}$ Libri. Tive um particular cuidado na sua arrumação, e mandei fazer dos livros ou folhetos mais miudos, varios embrulhos com a indicação das obras que encerrão. Estimarei que na Alfandega se não transtorne esse trabalho que m. ${ }^{\text {to }}$ servirá á VS. ${ }^{a}$ de verificar o que lhe mando. (Ibidem)

Depois de elencar os livros que não conseguiu encontrar, o agente explicou que incluiu os catálogos modernos "dos livreiros os mais acreditados de Paris” para que Franzini pudesse pedir livros no futuro, já que alguns dos que ele indicou na sua nota “ja não existem nem os fundos, nem as pessoas”. Além disso, explicava o agente, havia uma razão bastante forte para não se encontrar livros e, principalmente, folhetos na França de 1816.

durante a guerra última, a França precizada de generos coloniaes viu se obrigada a recorrer á Inglaterra, Napoleão concedia licenças p. ${ }^{a}$ a importação delles, más com a condição expressa de exportarem se de França generos de industria ou produção francezas que montasse a valor igual dos importados. Embarcavão-se pois Vinhos que nem para vinagre prestavão, alcaides de fabricas, de lojas, e de armazens, tudo foi varrido; por conseguinte livros máus, e mesmo alguns bons, forão embarcados p. ${ }^{a}$ a Inglaterra; mas apenas sahidas as embarcações, herão lançadas as suas carregações ao mar, e chegavão os navios em lastro à Inglaterra. A venda dos Generos aqui importados compensava essa perda; e saiba que ate se imprimirão livros com o destino de serem lançados ao mar (bem pode ajuizar do merecim. ${ }^{\text {to }}$ delles) e aos quaes davão os maganões o nome de edições ad usum 
Delphini nel Delphinorum; titulo que desdentão se dá a todo livro máu ou insipido, e que $\mathrm{m}^{\text {to }}$ avesso he do que os sabios conhecem no fronstispicio dos classicos impressos por ordem de Luis 14. (Ibidem, grifo do original)

O agente termina a carta, afirmando ter tomado a iniciativa de enviar a Franzini três livros que acreditou serem adequados, mas que, caso Franzini "não se [desse] por satisfeito com o recebimento dessas 3 obras", poderia entregá-las ao filho do agente, em Lisboa, e ser reembolsado.

Nenhuma outra fonte ou referência pode confirmar as afirmações de que, em algum momento das guerras napoleônicas, os navios ingleses lançaram livros ao mar, mas certamente as vicissitudes políticas da França (e da Europa), entre 1789 e 1815, provocaram mudanças constantes nas formas do comércio do livro, sem que seja possível perceber - ao menos na documentação analisada - qualquer impedimento do acesso ao livro, em especial, aos que contivessem idéias liberais, iluministas, revolucionárias ou simplesmente libertinas. A instabilidade política provocada pela Revolução Francesa e seus diversos desdobramentos, que culminaram com a ascensão do império napoleônico, fizeram que os livros seguissem por rotas diferentes ao longo dos anos estudados - predominantemente pela Itália, nas décadas finais do século XVIII, e através do comércio direto com a França, a partir do início do século XIX, em especial após a restauração dos Bourbon ao trono francês. Porém, a julgar pela documentação, Franzini obteve quase tudo o que desejava e as exceções dizem mais respeito a obras antigas e esgotadas do que a impedimentos relacionados a censura ou controle do comércio por parte do Estado.

Havia redes complexas em torno do comércio do livro, envolvendo agentes, representantes, livreiros, consignatários e compradores. Tratava-se de relações pessoais, no mais das vezes, envolvendo amizades, relações de parentesco (lembremos de Annetta Franzini, em Veneza) ou de interesses (Franzini mantinha contato com os redatores dos Annaes de Sciencias, em Paris, que atuaram como agentes em uma de suas compras de 1819, junto ao livreiro J. D. Mascarenhas). Franzini utilizou-se de forma constante dessas redes ao longo dos anos finais do século XVIII e dos anos iniciais do século XIX. Elas beneficiavam, simultaneamente, leitores e agentes do livro em geral, para quem auxiliavam a constituir hierarquias.

De facto, uma investigação fundada em registros notariais e de testamentos revela uma outra realidade, investida de uma autonomia própria, onde o mais importante parece ser o volume dos negócios, associado às capacidades de 
mobilização de crédito, de recursos a redes transnacionais, de aumento de escala e de exploração de oportunidades de negócio, de níveis de acumulação de capital conseguidosatravés deumadiversificaçãodeactividades, dealiançasmatrimoniais, etc. Nesta perspectiva, importam considerar, mas não exagerar, uma hierarquia tendo, na base, os cegos, a meio, os livreiros portugueses, e os mercadores franceses no topo. (Curto, 2007, p.237)

As pistas fornecidas por essa documentação reforçam a noção de que em Portugal a literatura filosófica iluminista e liberal encontrou ampla disseminação por mecanismos que variavam da compra direta, intermediada por livreiros, marinheiros e mercadores, até o contrabando e a contrafação realizada por imigrantes e agitadores liberais de diversas nacionalidades. A circulação de livros e idéias forneceu os elementos necessários para o surgimento do movimento liberal, em geral, e do Vintismo, em particular, como fica patente em uma análise detalhada da ação política de Marino Miguel Franzini e de outros estudos sobre a circulação da palavra impressa em Portugal no período. ${ }^{22}$

\section{NOTAS}

${ }^{1}$ ISRAEL, J. I. The intellectual drama in Spain and Portugal. In: Radical Enlightenment: philosophy and the making of modernity. 1650-1750. Oxford: Oxford University Press, 2001. p.528-540.

${ }^{2}$ RAMOS, L. O. Sob o signo das “luzes". Lisboa: Imprensa Nacional/Casa da Moeda, 1988. p.28.

${ }^{3}$ PEREIRA, J. E. Percursos de história das idéias. Lisboa: Imprensa Nacional/Casa da Moeda, 2004. p.93.

${ }^{4}$ VILLALTA, L. C. O império brasileiro e os brasis. São Paulo: Companhia das Letras, 2000. p.35.

${ }^{5}$ KURY, L. Homens de ciência no Brasil: impérios coloniais e circulação de informações (1780-1810). História, Ciências, Saúde - Manguinhos, Rio de Janeiro, v.11 (suplemento 1), p.109-129, 2004. Ver também: CHARTIER, R. The cultural origins of the French Revolution. New York: Duke University Press, 2004.

${ }^{6}$ CURTO, D. R. Cultura escrita: séculos XV a XVIII. Lisboa: Imprensa de Ciências Sociais, 2007. p.276. Ver também: LISBOA, J. L. Ciência e política: ler nos finais do Antigo Regime. Lisboa: Centro de História da Cultura da Universidade Nova de Lisboa, 1991. p.25.

${ }^{7}$ ANTUNES, A. A. Considerações sobre o domínio das letras nas Minas setecentistas. Lócus - Revista de história, Juiz de Fora, v.6, n.2, p.9-20, 2000. 
${ }^{8}$ RAMOS, 1988, p.137. Ver também: DARNTON, R. O iluminismo como negócio: história da publicação da "Enciclopédia", 1775-1780. São Paulo: Companhia das Letras, 1996.

${ }^{9}$ GUEDES, F. O livro e a leitura em Portugal: subsídios para a sua história - séculos XVIII e XIX. Lisboa: Verbo, 1987. p.79-80. Ver também: CURTO, 2007, p.290 ss.

${ }^{10}$ NUNES, M. F. O liberalismo português: ideário e ciências: o universo de Marino Miguel Franzini (1800-1860). Lisboa: Centro de História da Cultura da Universidade Nova de Lisboa, 1988. p.21. Ver também: MONTEIRO, A. C. Aspectos históricos da vida portuguesa: os professores doutores Miguel Franzini e Domingos Vandelli da Universidade de Coimbra através de alguns inéditos do Arquivo Nacional do Brasil. Revista do Arquivo Municipal, São Paulo, v.CXXIV, 1949.

${ }^{11}$ NUNES, 1988, p.17. Sobre aspectos da biografia de Marino Miguel Franzini, ver: URBAN, S. Gentleman's magazine. London: Bowyer Nichols and son, 1847, p.412. Dados gerais sobre sua carreira militar e científica podem ser encontrados em: REIS, F. Academia das Ciências de Lisboa. Disponível em: www.instituto-camoes.pt/cvc/ciencia/e31.html. Acesso em: 17 out. 2003; PORTUGAL. Dicionário Histórico. Disponível em: www.arqnet. pt/dicionario/franzinima.html. Acesso em: 17 out. 2003; FRANZINI, Marino Miguel. Disponível em: www.arqnet.pt/exercito/franzini.html. Acesso em: 17 out. 2003.

${ }^{12}$ FRANZINI, M. M. [Papéis que pertenceram a Marino Miguel Franzini] [Manuscrito] 1792-1832. Biblioteca Nacional. Lisboa. BN COD. 12934.

${ }^{13}$ DENIPOTI, C. Uma biblioteca vintista portuguesa e as influências do Iluminismo em Portugal no final do século XVIII e início do século XIX. In: PEREIRA, M. R.; SANTOS, A. C.; ANDREAZZA, M. L.; NADALIN, S. O. (Org.). VI Jornada Setecentista: conferências e comunicações. Curitiba: Aos Quatro Ventos; Cedope, 2006. p.191-199.

${ }^{14}$ FRANZINI, M. M. Rol dos livros que comecei a comprar em 1798. [Papéis que pertenceram a Marino Miguel Franzini] [Manuscrito] 1792-1832. Biblioteca Nacional. Lisboa. BN COD. 12934.

${ }^{15}$ TRIVELLATO, F. Juifs de Livourne, Italiens de Lisbonne, Hindous de Goa; réseaux marchands et échanges interculturels à l'époque moderne. Annales - Histoire, Sciences Sociales, v.58, n.3, p.581-604. mai-juin 2003.

${ }^{16}$ DARNTON, R. Os best-sellers proibidos da França pré-revolucionária. São Paulo: Companhia das Letras, 1998; DARNTON, R. Edição e sedição: o universo da literatura clandestina no século XVIII. São Paulo: Companhia das Letras, 1992; DARNTON, R. Boemia literária e revolução: o submundo das letras no Antigo Regime. São Paulo: Companhia das Letras, 1987.

${ }^{17}$ VILLALTA, L. C. Reformismo Ilustrado, censura e práticas de leitura: usos do livro na América Portuguesa. Tese (Doutorado em História) - Faculdade de Filosofia, Letras e Ciências Humanas (FFLCH), Universidade de São Paulo. São Paulo, 1999. 640f. p.198 ss.

${ }^{18}$ BAUMER, Franklin. O pensamento europeu moderno. 2v. Lisboa: Edições 70, s.d., p.180, grifo do original. 
${ }^{19}$ FRANZINI, M. M. Fatura. In: [Papéis que pertenceram a Marino Miguel Franzini] [Manuscrito] 1792-1832. Biblioteca Nacional. Lisboa. BN COD. 12934.

${ }^{20}$ SANTINI FIGLIO, Andrea. Fatura. In: FRANZINI, M. M. [Papéis que pertenceram a Marino Miguel Franzini] [Manuscrito] 1792-1832. Biblioteca Nacional. Lisboa. BN COD. 12934.

${ }^{21}$ ANON. Fatura dos livros comprados por contas e ordem do $\mathrm{Ill}^{\mathrm{mo}}$. Sr. Marino Miguel Franzini, Ten. ${ }^{\text {te }}$ Coronel da Brigada R. ${ }^{1}$ da Marinha em Lisboa. In: FRANZINI, M. M. [Papéis que pertenceram a Marino Miguel Franzini] [Manuscrito] 1792-1832. Biblioteca Nacional. Lisboa. BN COD. 12934, grifo do original.

${ }^{22}$ Ver NUNES, 1988; CURTO, D. R. A história do livro em Portugal: uma agenda em aberto. Leituras - Rev. Bibl. Nac., Lisboa, v.3, n.9-10, p.13-61, out. 2002.

Artigo recebido em maio de 2008. Aprovado em setembro de 2008. 